\title{
Inhibitory effects of Aristotelia chilensis water extract on 2,4-Dinitrochlorobenzene induced atopic-like dermatitis in $\mathrm{BALB} / \mathrm{c}$ Mice
}

\author{
Hyun-Deok Moon, Bae-Hwan Kim
}

\begin{abstract}
Background: Maqui berry (Aristotelia chilensis) has been reported to have anti-glycation, anti-inflammation, lipogenesis-inhibiting activities highly related to its anti-oxidation function, but practical efficacy studies on immunological mechanisms for atopic dermatitis, have not been reported yet.
\end{abstract}

Objective: This study investigated the immune regulation mechanism of Aristotelia chilensis water extract (ACWE) related to atopic-like dermatitis

Methods: Antioxidant and anti-inflammatory effects of ACWE was assayed. Atopy inhibitory effect was evaluated using in vitro cell study and in vivo 2,4-dinitrochlorobenzene (DNCB)-induced mouse atopic-like dermatitis model.

Results: ACWE has good antioxidant activities, and atopic indications were improved in ACWE group in DNCB-induced atopic-like dermatitis model of BALB/c mice. In spleen cells from mice, ACWE increased interferon-gamma (IFN- $\gamma$ ) levels, and decreased interleukin-4 (IL-4) levels compared with the DNCB control.

Conclusion: ACWE was efficacious for atopic dermatitis which indicates that ACWE might have potential as an agent for atopic dermatitis.

Key words: atopic like dermatitis, DNCB, BALB/c mice, Maqui Berry (Aristotelia chilensis), anti-inflammation

From:

Department of Public Health, College of Natural Science, Keimyung University, Daegu, 42601, Republic of Korea
Corresponding author:

Bae-Hwan Kim

Department of Public Health, College of Natural Science, Keimyung University, Daegu, 42601, Republic of Korea

E-mail: kim9399@kmu.ac.kr

\section{Introduction}

Atopic dermatitis is a chronic disease with recurrent skin eczema. Its related symptoms include pruritus, erythematous papules, and dryness. The cause of atopic dermatitis can be divided into environmental cause and genetic cause. ${ }^{1}$ The obvious etiology associated with atopic dermatitis is currently unknown. However, it is known that atopic dermatitis is a skin disease immunologically sensitive to external antigens. ${ }^{2}$ Atopic dermatitis is mainly observed in infancy and childhood. However, it can continue or develop in adults. Its prevalence is increasing recently, especially in industrially advanced countries. $^{3} \mathrm{~A}$ recent report has shown that the cause of abnormalities of skin surface barrier is a pathogenesis of atopic skin inflammation, with study on its immunological mechanism involving stratum corneum component currently in progress. ${ }^{4}$
The moisture content of the skin is about $15 \%$ for normal people. When water content is lower than $10 \%$, reduced ceramide concentration in the stratum corneum can cause xeroderma and pruritus. These symptoms can also cause secondary skin disease, leading to cell-mediated inflammation in response to allergen and pathogen infiltration. ${ }^{5}$

In atopic dermatitis, immune related factors interact with each other. They are involved in skin inflammation. Typical relevant factors including $\mathrm{T}$ lymphocyte, immunoglobulin $\mathrm{E}$ (IgE), and cytokines expressed by helper T cell type 1 (Th1 cell) and helper T cell type 2 (Th2 cell). ${ }^{6}$

Helper T cells are classified into Th1 and Th2 cells according to the classification of released cytokines. Th1 cells express cytokines such as tumor necrosis factor (TNF), interleukin 
(IL)-2, and interferon-gamma (IFN- $\gamma$ ) that can activate macrophages to induce subacute dermatitis. ${ }^{7}$ Th2 cells induce hypersensitivity by expressing cytokines such as IL-4, IL-5, IL6, IL-10. They cause differentiation of eosinophils and mast cells. In addition, they can increase the production of IgE. ${ }^{8}$ In general, a balanced immune response is maintained by intercellular interactions. However, inflammatory responses of atopic dermatitis are induced and promoted by increased Th2 cell cytokines. ${ }^{9}$ In short, changes in IgE levels in atopic dermatitis and expression levels of cytokines such as IL-4 might be important for developing treatment and mitigation strategies for this disease. ${ }^{9}$

Immunosuppressants, topical steroids, and anti-histamines are usually used for atopic dermatitis. However, it has been reported that those drugs can cause various side effects. ${ }^{10-12}$ Therefore, there is a need to develop new safe drugs to improve atopic dermatitis. In recent years, safe natural materials as atopic dermatitis medication have been reported at home and abroad and their anti-inflammatory effects have been confirmed by immunological analysis using atopic dermatitis mice model. ${ }^{13,14}$ Natural-derived substances that can relieve atopic dermatitis usually have less side effects.

The maqui berry (Aristotelia chilensis), a purple food, is generally being ingested in the form of liquidized juice or dry powder, ${ }^{15}$ and is rich in purple anthocyanin and polyphenol. Its antioxidant index is about 7 times higher than that of acai Berry and 6.6 times higher than that of aronia. It is an excellent antioxidant. Currently, previous studies have reported that Aristotelia chilensis has anti-glycation, anti-inflammation, lipogenesis-inhibiting activities highly related to its anti-oxidation function, ${ }^{16-18}$ but practical efficacy studies on immunological mechanisms of Aristotelia chilensis for skin related diseases, especially atopic dermatitis, have not been reported yet.

Therefore, the objective of this study was to evaluate the anti-inflammatory effect and immunological regulation mechanism of Aristotelia chilensis water extract (ACWE) for atopic dermatitis using in vitro cell study and in vivo 2,4-dinitrochlorobenzene (DNCB)-induced atopic-like dermatitis mouse model to determine its potential as a medication agent for atopic dermatitis.

\section{Materials and methods \\ Reagents and apparatus}

Dulbecco's modified eagle's medium (DMEM), fetal bovine serum (FBS), penicillin/streptomycin (P/S) and RPMI-1640 medium were obtained from Lonza (Walkersville, MD, USA), and Milliplex mouse cytokine/chemokine magnetic bead panel was purchased from Millipore (Billerica, MA, USA). $\mathrm{CO}_{2}$ incubator (MCO-17AIC, Sanyo, Japan), clean bench (DBB-922, Daeil, Korea), cryogenic centrifuge (VS-550, Vision Science, Korea), optical microscope (DM500, Leica, Germany), microsurgery machine (RM2235, Leica, Germany), and automatic immune stainer (Roche-Ventana, Benchmark, USA) devices were also used in this study.

\section{Preparation of Aristotelia chilensis water extract (ACWE)}

Aristotelia chilensis (Chilean freeze-dried power 99.9\%) was purchased from Gabdang Herb Co. Ltd. (Korea). For hot water extraction, $100 \mathrm{~g}$ of the powder material was mixed with $1 \mathrm{~L}$ of water for 3 hours at $80^{\circ} \mathrm{C}$, repeatedly extracted three times, and filtered to prepare ACWE. ACWE was then freeze-dried to powder for 72 hours. The major component of the extract Aristotelia chilensis was known as anthocyanin, which contained the highest amount of delphinidin. ${ }^{16}$

\section{Antioxidant activity measurement}

Total polyphenol and flavonoid contents were measured according to Folin-Denis experimental method. ${ }^{19}$ Electrondonating ability was measured with method of Blois, ${ }^{20}$ and Free radical scavenging activity was measured using ABTS+ cation decolorization assay. ${ }^{21}$ Electron-donating ability and radical scavenging activity of each sample were determined using the following equation based on absorbance values of experimental solution and control solution:

$$
\text { Results }(\%)=\left[1-\left(\mathrm{A}_{\text {sample }} / \mathrm{A}_{\text {control }}\right)\right] \times 100
$$

where $\mathrm{A}_{\text {control }}$ was the absorbance of the control (reagents without test compound).

\section{Anti-inflammatory experiment in RAW 264.7 cells $^{22}$}

RAW 264.7 (Korean Cell Line Bank, KCLB 40071, Seoul, Korea) cells of mouse macrophage cell line, were cultured in DMEM supplemented with $10 \% \mathrm{FBS}$ and $1 \% \mathrm{P} / \mathrm{S}$ at $37^{\circ} \mathrm{C}$ supplemented with $5 \% \mathrm{CO}_{2}$. Cytotoxicities of several dose of ACWE were measured by MTT assay, and cytotoxicities of LPS with/without ACWE were also measured by MTT assay in RAW 264.7 cells. For anti-inflammatory experiment, RAW 264.7 cells were seeded into 96 -well cell culture plate at density of $1 \times 10^{5}$ cells/well and cultured at $37^{\circ} \mathrm{C}$ for 24 hours in a $5 \% \mathrm{CO}_{2}$ incubator. Samples were diluted in DMEM supplemented with LPS $(0.1 \mu \mathrm{g} / \mathrm{mL})$ and added to each well $(200$ $\mu \mathrm{L} /$ well) followed by incubation at $37^{\circ} \mathrm{C}$ for 24 hours in the $5 \% \mathrm{CO}_{2}$ incubator. After taking out $100 \mu \mathrm{L}$ of culture supernatant from each well, Griess reagent $(100 \mu \mathrm{L})$ was added followed by incubation at room temperature for 10 minutes. Absorbance was measured at wavelength of $540 \mathrm{~nm}$ using an ELISA plate reader. Nitric oxide (NO) concentration in cell culture supernatant was calculated from a quantitative curve using $\mathrm{NaNO}^{2}$ standard $\left(\mathrm{y}=0.0161 \mathrm{x}+0.0115, \mathrm{R}^{2}=0.992\right)$.

\section{Oxazolone-induced subacute inflammatory animal model Experimental animals and grouping}

Seven-week-old male BALB/c mice (Samtako Co. Ltd., Osan, Korea) were used after one week acclimation in a barrier system room with controlled environmental conditions (temperature $22 \pm 3^{\circ} \mathrm{C}$, humidity $50 \pm 5 \%$, dark and light cycle; 12:12 hours). Food (Purina, Korea) and water were supplied ad libitum during the experiment. All animal experiment procedures were approved by Institutional Animal Care and Use Committee (IACUC) of Keimyung University. 
Using a randomized block design (RBD), the following groups (five mice per group) were constructed: NC) non-treatment group, mice did not receive any treatment; $\mathrm{CO}$ ) control group, subacute dermatitis were induced with oxazolone; VC) vehicle control group, mice were treated by vehicle after inducing subacute dermatitis with oxazolone; PC) positive control group, mice were treated with $0.5 \%$ dexamethasone (Sigma-Aldrich, St. Louis, MO, USA) after inducing subacute dermatitis with oxazolone; E1) experimental 1 group, mice were treated with $1 \%$ ACWE after inducing subacute dermatitis with oxazolone; E2) experimental 2 group, mice were treated with 5\% ACWE after inducing subacute dermatitis with oxazolone; E3) experimental 3 group, mice were treated with $10 \%$ ACWE after inducing subacute dermatitis with oxazolone.

\section{Anti-inflammatory effects of ACWE in subacute skin inflam- mation model}

After hair at the ear area was shaved at weekly intervals, oxazolone solution $(2 \%, 50 \mu \mathrm{L})$ dissolved in acetone was applied to the shaved ear area of mouse at day 1 and day 2 to induce subacute skin inflammation. On the sixth day of the experiment, $20 \mu \mathrm{L}$ of $2 \%$ oxazolone solution was applied to same area of mouse to induce subacute dermatitis. At 15 minutes and 6 hours after application of 2\% oxazolone solution, test material in acetone $(20 \mu \mathrm{L})$ at various concentrations was applied to the same area.

At 24 hours after challenge with $20 \mu \mathrm{L}$ of $2 \%$ oxazolone solution on the six day, mice were euthanized by cervical dislocation. Ear thickness and ear weight were measured after biopsy punch $(6 \mathrm{~mm})$. Percent of inhibition was calculated using the following formula:

$$
\begin{aligned}
& \text { Percent of inhibition }(\%)=1-\frac{\text { Test site }- \text { Non treated site }}{\text { Oxazolone only treated site - }} \\
& \text { Non treated site }
\end{aligned}
$$

\section{Optical microscope observation after hematoxylin and eosin (H\&E) staining}

Skin tissue from autopsy was fixed in 10\% formalin for 24 hours and embedded in paraffin with standard process. Embedded tissue was cut into sections at thickness of $4 \mu \mathrm{m}$ and stained with H\&E. Changes of skin tissue such as epidermal thickness and inflammatory cell infiltration were observed under an optical microscope.

\section{DNCB induced atopic-like dermatitis model \\ Experimental animal and grouping}

Five-week-old male BALB/c mice (Samtako Co. Ltd., Osan, Korea) were used after one week acclimation in the barrier system room with controlled environment, and food and water were supplied ad libitum during the experiment. All experiment procedures were approved by IACUC of Keimyung University.

Using randomized block design (RBD), the following experimental groups (six mice per group) were constructed: N) non-treatment group, mice did not receive any treatment; $\mathrm{C}$ ) control group, atopic-like dermatitis was induced in mice with
DNCB; VC) vehicle control group, mice were treated with acetone:olive oil $=4: 1(\mathrm{AOO})$ after inducing atopic-like dermatitis with DNCB; PC) positive control group, mice were treated with $0.5 \%$ dexamethasone after inducing atopic-like dermatitis with DNCB; T1) test group 1, mice were treated with $1 \%$ ACWE after inducing atopic-like dermatitis with DNCB; T2) test group 2, mice were treated with 6\% ACWE after inducing atopic-like dermatitis with DNCB.

\section{Atopic-like dermatitis induction and ACWE application}

DNCB solution $(1 \%, 150 \mu \mathrm{L})$ in vehicle (AOO) was applied to the shaved back skin area of mouse twice with 3-day interval to sensitize atopic-like dermatitis. In the next week, $0.2 \%$ DNCB solution was applied to the same area twice with 3-day interval to challenge atopic-like dermatitis. After that, $150 \mu \mathrm{L}$ of dexamethasone and ACWE were applied to the back skin area five times a week for six weeks. To prevent auto recovery of atopic-like dermatitis, $0.2 \%$ of DNCB solution was treated once a week during the treatment period. Water intake, feed intake, and weight change were measured once a week at $10 \mathrm{am}$.

\section{Macroscopic examination of anti-atopic effects}

Behavioral characteristics such as scratching frequency at the back skin area using hind legs were observed for 30 minutes right before ACWE application and at the end of the experiment. Trans-epidermal water loss (TEWL) and erythema index was measured by tewameter (CM825, CK electronic $\mathrm{GmbH}$, Germany) and mexameter (MX18, CK electronic $\mathrm{GmbH}$, Germany) right before ACWE application and at the end of the experiment for the back area using non-invasive method.

For the visualization of skin lesion, skin was photographed under anesthesia once a week to check skin lesion at the shaved area by the SCORAD index. ${ }^{23}$ Symptoms of atopic-like dermatitis were macroscopically observed. Symptoms were classified as nonspecific (0), mild (1), intermediate (2), and severe (3) according to SCORAD index evaluation for symptoms such as erythema, edema, exfoliation, abrasion, lichenification and dryness.

\section{Blood sampling and serum IgE measurement}

Approximately $100 \mu \mathrm{L}$ of blood was collected from the retro-orbital plexus and centrifuged. Obtained serum was stored at $-80^{\circ} \mathrm{C}$ for further analysis. Frozen serum was immediately thawed and levels of IgE levels were quantified using enzyme-linked immunospecific assay (ELISA) kit (Sibayagi company, Japan) following the manual. Absorbance was measured at wavelength of $450 \mathrm{~nm}$ using an ELISA plate reader.

\section{Spleen cell culture and cytokine measurement}

Spleen was extracted from animal after autopsy and washed with RPMI-1640 medium. Washed spleen was lightly crushed with sterilized glass to separate cells. Cell suspension was passed through $70 \mu \mathrm{m}$ nylon cell strainer and centrifuged at $1,500 \mathrm{rpm}$ for 15 minutes. After removing supernatant, red blood cells were removed using lysis buffer. Remaining cells were washed three times. Experimental procedure for red blood cells removal was performed at $24^{\circ} \mathrm{C}$. 
Other procedures of the experiment were performed at $4^{\circ} \mathrm{C}$. Cell culture plate (24-well) was coated with $1.25 \mu \mathrm{g} / 500 \mu \mathrm{L}$ of CD3e per well for 24 hours. RPMI-1640 medium containing $10 \%$ FBS, $1 \mathrm{mM}$ sodium pyruvate, $50 \mathrm{mM}$ 2-mercaptoethanol, $1 \% \mathrm{P} / \mathrm{S}, 7.5 \%$ sodium bicarbonate solution, and MEM non-essential amino acid solution was used for cell culture. Spleen cells at density of $2 \times 10^{6}$ cells/well were seeded into 24 -well cell culture plate coated with $\mathrm{CD} 3 \mathrm{e}(1 \mathrm{~mL}$ per well) and incubated at $37^{\circ} \mathrm{C}$ with $5 \% \mathrm{CO}_{2}$ for 48 hours. After confirming that cells grew well, culture supernatant was stored at $-80^{\circ} \mathrm{C}$. Levels of cytokines secreted by spleen cells of mice were measured using Milliplex mouse cytokine/chemokine magnetic bead panel (Millipore, Billerica, MA, USA). Levels of cytokines IFN- $\gamma$ and IL-4 were measured on a Luminex 200 instrument. Ratios between IFN- $\gamma$ versus IL- 4 were also calculated when the ratio of $\mathrm{N}$ group was converted into 100 .

\section{Skin histopathological observation}

Skin tissue from autopsy was fixed in $10 \%$ formalin for 24 hours and embedded in paraffin with common process. Embedded tissue was cut into $4 \mu \mathrm{m}$ thick sections and stained with $H \& E$. Changes of skin tissue such as epidermal thickness and inflammatory cell infiltration were observed under an optical microscope. After toluidine blue staining, distribution and degranulation patterns of mast cells in dermis were observed. These histological observations proceeded with reference to the previous report. ${ }^{24}$

\section{Statistical analysis}

SPSS 21.0 for windows (SPSS Inc., USA) statistical program was used to perform one-way analysis of variance (ANOVA) to analyze differences among group means. Tukey-Kramer multiple range test was used to determine differences between groups. Statistical significance level of this study was set at $p<0.05$.

\section{Results}

\section{Antioxidant activity of ACWE}

Total polyphenol and total flavonoid contents of ACWE were $65.53 \mathrm{mg} / \mathrm{g}$ and $33.99 \mathrm{mg} / \mathrm{g}$ each. Electron-donating ability was $97.5 \%$ at $1000 \mathrm{ppm}$ which was similar to that of ascorbic acid. ABTS+ radical scavenging ability was $99.6 \%$ at 1000 ppm.

\section{Anti-inflammatory effect of ACWE in RAW 264.7 cells}

Cell viability of RAW 264.7 cells was $94.2 \%$ after treatment with ACWE at dose of $2000 \mathrm{ppm}$ which was used to determine its NO inhibitory effect. Cell viabilities of RAW 264.7 cells after treated with LPS and ACWE at doses of 62.5, 125, 250, 500, 1000, and $2000 \mathrm{ppm}$, were 97.9\%, 95.0\%, 90.4\%, $91.5 \%, 89.1 \%$, 90.0\%, respectively. Cells treated with LPS only showed $95.98 \%$ viability.

NO production was inhibited by ACWE in a dose-dependent manner, and showed 29.3\% inhibition by ACWE at 2000 ppm (Figure 1).

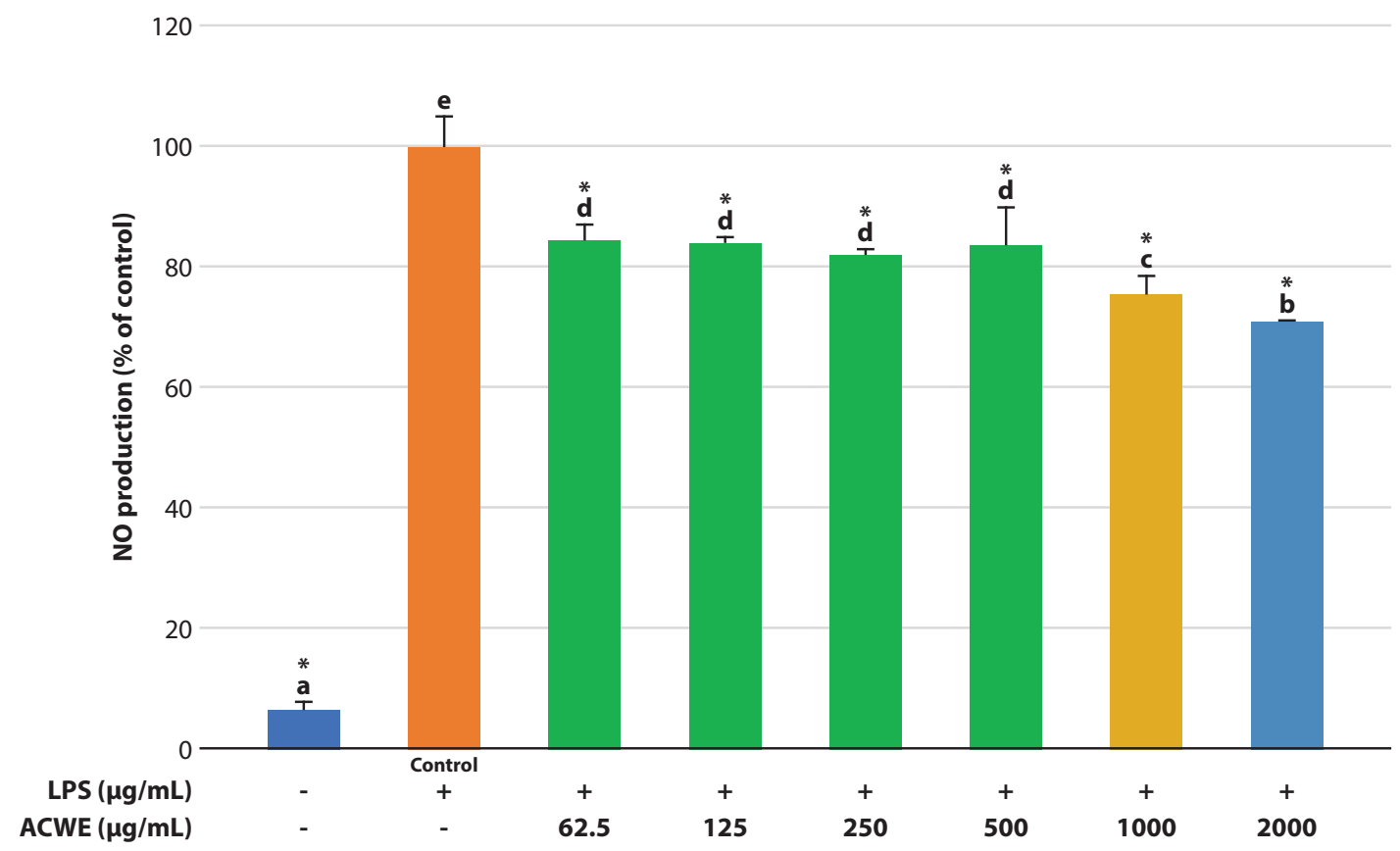

Figure 1. Effects of ACWE on NO production in LPS-stimulated RAW 264.7 cells. ACWE: Aristotelia chilensis water extract. Control: only LPS-treatment control. The values represent mean \pm SD of three independent experiments. Values with different letters $(\mathrm{a}, \mathrm{b}, \mathrm{c}, \mathrm{d}, \mathrm{e})$ are significantly different $(\mathrm{p}<0.05)$ by ANOVA and Tukey-Kramer test. ${ }^{\star} \mathrm{p}<0.05$ as compared to the Control group by ANOVA and Tukey-Kramer test. 


\section{Oxazolone-induced subacute inflammatory effects in mice}

Ear thickness was increased in CO and VC groups, but decreased markedly in ACWE treated groups in a dose dependent manner. It was also decreased in PC group. In PC group, ear thickness inhibition rate was $84.7 \%$. In groups treated with $\mathrm{ACWE}$ at $1 \%, 5 \%$, and $10 \%$, ear thickness inhibition rates were $48.8 \%, 51.3 \%$, and $69.3 \%$, respectively. Ear weight inhibition rate was $46.4 \%$ in PC group. In groups treated with ACWE at 1\%, 5\%, and 10\%, ear weight inhibition rates were $25.5 \%, 29.8 \%$, and $28.1 \%$, respectively.

The epidermis thickness was increased in CO group and VC group treated with oxazolone only. Infiltration of many inflammatory cells was observed in ear epidermis of $\mathrm{CO}$ group and VC group treated with oxazolone only, but greatly decreased in E and PC groups compared to those in CO and VC groups (Figure 2).
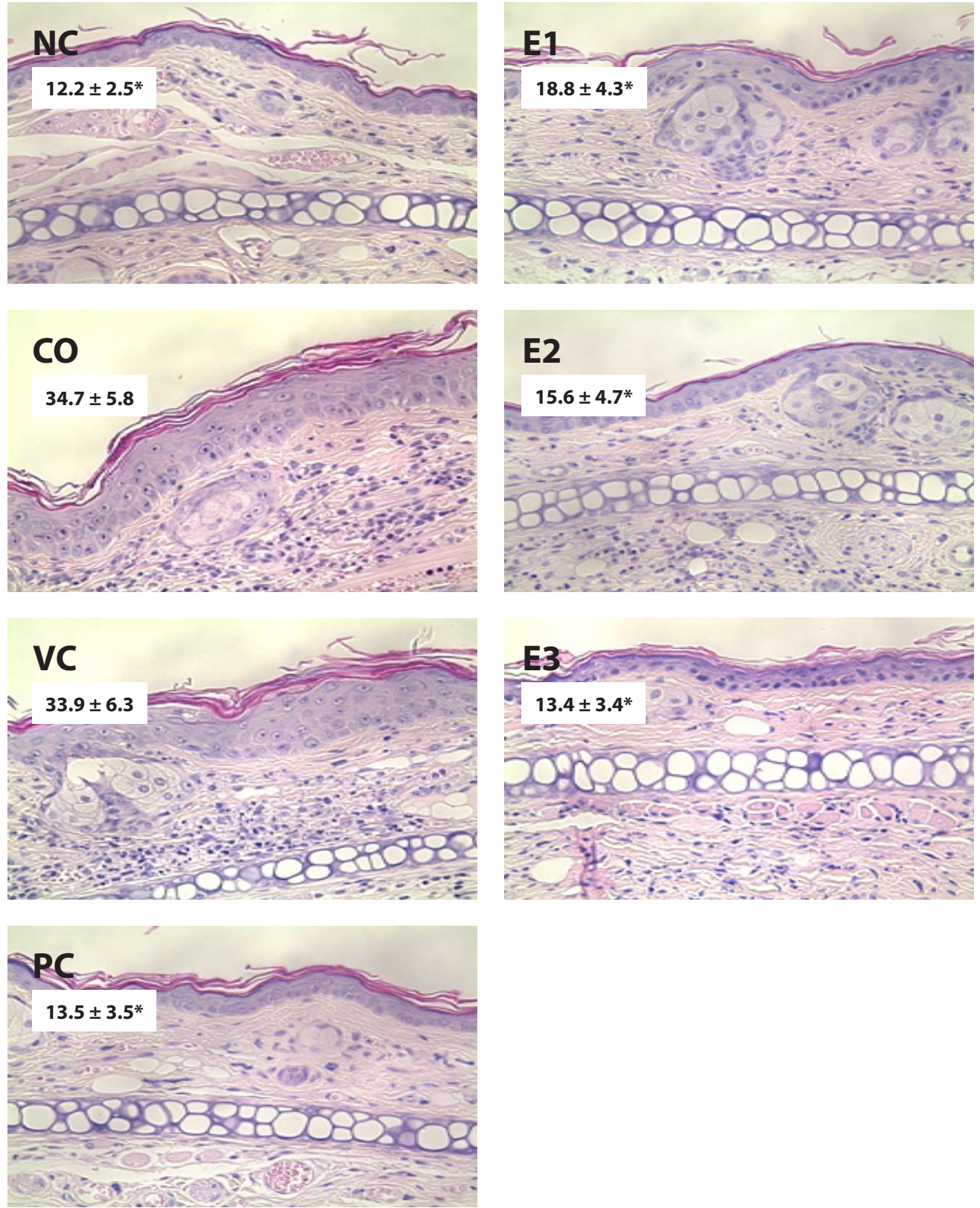

Figure 2. The histological examination of skin after treatment of ACWE in oxazolone-induced subacute inflammatory test. H\&E stain, $\times$ 400. NC: Non-treatment, CO: Oxazolone, VC: Oxazolone + AOO (acetone : olive oil = 4: 1), PC: Oxazolone + 0.5\% Dexamethasone, E1: Oxazolone + 1\% ACWE, E2: Oxazolone + 5\% ACWE, E3: Oxazolone + 10\% ACWE. ACWE: Aristotelia chilensis water extract. Bar: $10 \mu \mathrm{M}$. Epidermal thickness was determined by the average of three sites (short, medium, long-size each) in same fields of microscope, and values are mean \pm SD of skin epidermis thickness of 5 mice. ${ }^{\star} p<0.05$ as compared to the CO group by ANOVA and Tukey-Kramer test. 


\section{DNCB induced atopic-like dermatitis model}

\section{Anti-itching effects of ACWE}

Clinical abnormality was not observed during experiment except for body weight decrease in T and PC groups. Scratching frequencies in $\mathrm{PC}$ and $\mathrm{T}$ groups were decreased significantly after 6 weeks of ACWE treatment compared to those in the control group (Table 1).

\section{Measurement of TEWL and erythema}

Values of TEWL and erythema were increased in atopic-like dermatitis induced groups (C). After the end of the experiment, values were decreased in all groups except in VC group (Table 2 ).

\section{Visualization of skin lesion}

Recovery aspect was observed in $\mathrm{PC}$ and $\mathrm{T}$ groups in the $2^{\text {nd }}$ week of ACWE treatment. At the $6^{\text {th }}$ week, skin lesions in $\mathrm{T}$ groups were recovered, similar to those in $\mathrm{N}$ group (Figure 3).

\section{Serum IgE measurement}

After inducing atopic-like dermatitis, IgE levels were increased (about 2.5 times) compared to those in $\mathrm{N}$ group. However, there was no significant difference in IgE level among all groups. At 6 weeks after ACWE treatment, IgE levels in $\mathrm{T}$ groups and $\mathrm{PC}$ groups were decreased compared to those in $\mathrm{C}$ and $\mathrm{VC}$ groups (Table 2).

\section{Spleen cell culture and cytokine measurement}

IFN- $\gamma$ levels were significantly increased in $\mathrm{T}$ groups and PC group compared to those in C and VC groups. IL-4 levels were significantly decreased in $\mathrm{T}$ groups and $\mathrm{PC}$ group compared to those in $\mathrm{C}$ and $\mathrm{VC}$ groups (Table 3 ). The ratio of IFN- $\gamma$ versus IL-4 was significantly decreased compared to that in $\mathrm{N}$ group. However, this ratio was significantly increased in $\mathrm{T}$ and $\mathrm{PC}$ groups.

Table 1. Scratching frequency before 0 week and after 6 weeks in DNCB induced atopic-like dermatitis model

\begin{tabular}{cccccccc} 
& \multicolumn{7}{c}{ Groups } \\
\cline { 2 - 7 } Weeks & $\mathbf{N}$ & $\mathbf{C}$ & VC & PC & T1 & T2 \\
\cline { 2 - 7 } & $2.0 \pm 0.70^{\text {a* }}$ & $14.2 \pm 4.44^{\mathrm{b}}$ & $13.3 \pm 3.27^{\mathrm{b}}$ & $13.33 \pm 3.78^{\mathrm{b}}$ & $13.5 \pm 2.17^{\mathrm{b}}$ & $14.0 \pm 4.34^{\mathrm{b}}$ \\
\hline 6 & $2.4 \pm 1.00^{\mathrm{a} *}$ & $16.8 \pm 5.26^{\mathrm{c}}$ & $15.7 \pm 2.34^{\mathrm{c}}$ & $5.80 \pm 2.59^{\mathrm{b} *}$ & $9.17 \pm 1.72^{\mathrm{b} *}$ & $9.67 \pm 3.33^{\mathrm{b} *}$ \\
\hline
\end{tabular}

Unit: number. Values are mean \pm SD of 5 mice. Test compounds were topically applied to the backs of BALB/c mice during 6 weeks.

$\mathrm{N}$ : Non-treatment, C: DNCB, VC: DNCB + AOO (acetone:olive oil = 4:1), PC: DNCB + 0.5\% Dexamethasone, T1: DNCB + 1\% ACWE, T2: DNCB + 6\% ACWE. ACWE: Aristotelia chilensis water extract.

Values with different letters $(\mathrm{a}, \mathrm{b}, \mathrm{c})$ of same row are significantly different $(p<0.05)$ by ANOVA and Tukey-Kramer test. ${ }^{*} p<0.05$ as compared to the C group by ANOVA and Tukey-Kramer test.

Table 2. The changes of TEWL, erythema and serum IgE levels in BALB/c mouse of DNCB induced atopic-like dermatitis model during 6-week treatment

\begin{tabular}{|c|c|c|c|c|c|c|c|}
\hline & \multirow{2}{*}{ Weeks } & \multicolumn{6}{|c|}{ Groups } \\
\hline & & $\mathbf{N}$ & C & VC & PC & T1 & T2 \\
\hline \multirow[t]{2}{*}{ TEWL } & 0 & $12.76 \pm 2.23^{\mathrm{a} \star}$ & $35.86 \pm 4.12^{\mathrm{b}}$ & $43.51 \pm 6.39^{c \star}$ & $44.30 \pm 5.21^{c *}$ & $42.52 \pm 6.82^{c *}$ & $37.87 \pm 3.61^{b c}$ \\
\hline & 6 & $13.16 \pm 2.11^{\text {aौ }}$ & $50.76 \pm 12.72^{c}$ & $52.15 \pm 12.86^{c}$ & $14.78 \pm 1.94^{\mathrm{a} \star}$ & $24.92 \pm 10.40^{\mathrm{ab} \star}$ & $28.17 \pm 6.82^{b *}$ \\
\hline \multirow[t]{2}{*}{ Erythema } & 0 & $166.8 \pm 3.49^{a \star}$ & $217.8 \pm 13.70^{\mathrm{b}}$ & $228.5 \pm 14.27^{\mathrm{b}}$ & $226.8 \pm 19.28^{\mathrm{b}}$ & $229.3 \pm 25.67^{\mathrm{b}}$ & $216.8 \pm 22.01^{b}$ \\
\hline & 6 & $179.4 \pm 10.55^{\mathrm{a} \star}$ & $261.4 \pm 21.10^{c}$ & $277.5 \pm 21.38^{c}$ & $228.4 \pm 10.01^{\mathrm{b} *}$ & $216.5 \pm 13.90^{\mathrm{b} *}$ & $220.2 \pm 28.87^{b *}$ \\
\hline \multirow[t]{2}{*}{ Serum IgE levels } & 0 & $23.14 \pm 13.32^{\mathrm{a} \star}$ & $47.64 \pm 18.43^{b}$ & $52.05 \pm 5.11^{\mathrm{b}}$ & $47.09 \pm 15.27^{\mathrm{b}}$ & $47.43 \pm 8.15^{\mathrm{b}}$ & $52.58 \pm 15.96^{\mathrm{b}}$ \\
\hline & 6 & $24.94 \pm 8.49^{a \star}$ & $44.43 \pm 8.45^{\mathrm{bc}}$ & $53.16 \pm 15.73^{c}$ & $27.81 \pm 9.47^{a \star}$ & $33.73 \pm 7.32^{\mathrm{ab}}$ & $31.61 \pm 8.60^{\mathrm{a} *}$ \\
\hline
\end{tabular}

Unit: TEWL $\left(\mathrm{g} / \mathrm{h} / \mathrm{m}^{2}\right.$ ), Erythema (AU, arbitrary unit), serum IgE (ng/mL). Values are mean \pm SD of 5 mice. Test compounds were topically applied to the backs of $\mathrm{BALB} / \mathrm{c}$ mice during 6 weeks (week 0 : after induction of atopic dermatitis, week 6: after application of test substances).

$\mathrm{N}$ : Non-treatment, C: DNCB, VC: DNCB + AOO (acetone : olive oil = 4: 1), PC: DNCB + 0.5\% Dexamethasone, T1: DNCB + 1\% ACWE, T2: DNCB + 6\% ACWE. ACWE: Aristotelia chilensis water extract.

Values with different letters $(\mathrm{a}, \mathrm{b}, \mathrm{c})$ of same row are significantly different $(p<0.05)$ by ANOVA and Tukey-Kramer test. ${ }^{\star} p<0.05$ as compared to the C group by ANOVA and Tukey-Kramer test. 


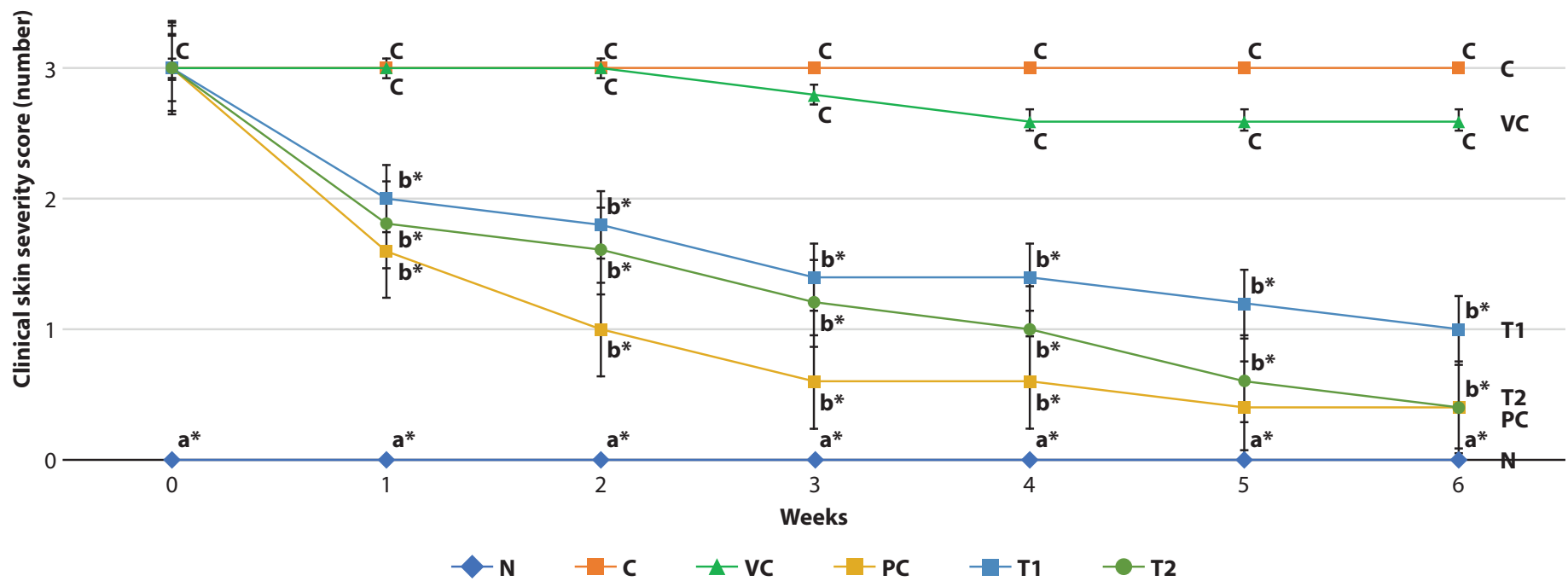

Figure 3. The changes comparison in score index during the experimental period of DNCB induced atopic-like dermatitis model. Values are mean \pm SD of 6 mice. N: Non-treatment, C: DNCB, VC: Oxazolone + AOO (acetone : olive oil = 4: 1), PC: DNCB + 0.5\% Dexamethasone, T1: DNCB + ACWE 1\%, T2: DNCB + ACWE 6\%. Values with different letters (a, b, c) of same row are significantly different $(\mathrm{p}<0.05)$ by ANOVA and Tukey-Kramer test. ${ }^{\star} \mathrm{p}<0.05$ as compared to the C group by ANOVA and Tukey-Kramer test.

Table 3. Levels of IFN- $\gamma$ and IL-4 in mouse spleen cells of DNCB induced atopic-like dermatitis model

\begin{tabular}{ccccccc} 
& \multicolumn{5}{c}{ Groups } \\
\cline { 2 - 6 } & N & C & VC & PC & T1 \\
IFN- $\gamma$ & $91.41 \pm 16.62^{\mathrm{d} *}$ & $51.86 \pm 6.83^{\mathrm{a}}$ & $59.12 \pm 15.56^{\mathrm{ab}}$ & $79.42 \pm 18.13^{\mathrm{cd} *}$ & $70.23 \pm 32.25^{\mathrm{abc}}$ & $72.53 \pm 22.93^{\mathrm{bc} *}$ \\
IL-4 & $45.60 \pm 11.57^{\mathrm{a} *}$ & $98.46 \pm 37.71^{\mathrm{c}}$ & $86.42 \pm 21.95^{\mathrm{bc}}$ & $57.06 \pm 15.20^{\mathrm{ab} *}$ & $75.70 \pm 55.78^{\mathrm{bc}}$ & $66.25 \pm 21.41^{\mathrm{ab} *}$ \\
\hline IFN- $\gamma$ versus IL-4 & $100.00 \pm 26.74^{\mathrm{c} *}$ & $27.91 \pm 9.84^{\mathrm{a}}$ & $34.81 \pm 13.54^{\mathrm{a}}$ & $69.27 \pm 20.08^{\mathrm{b} *}$ & $55.12 \pm 21.36^{\mathrm{ab}}$ & $56.20 \pm 24.77^{\mathrm{b} *}$ \\
\hline
\end{tabular}

Unit: pg/mL. Values are mean $\pm \mathrm{SD}$ of 5 mice.

N: Non-treatment, C: DNCB, VC: DNCB + AOO (acetone : olive oil = 4: 1), PC: DNCB + 0.5\% Dexamethasone, T1: DNCB + 1\% ACWE, T2: DNCB + 6\% ACWE. Values with different letters $(\mathrm{a}, \mathrm{b}, \mathrm{c}, \mathrm{d})$ are significantly different $(p<0.05)$ by ANOVA and Tukey-Kramer test. ${ }^{\star} p<0.05$ as compared to the C group by ANOVA and Tukey-Kramer test.

\section{H\&E}

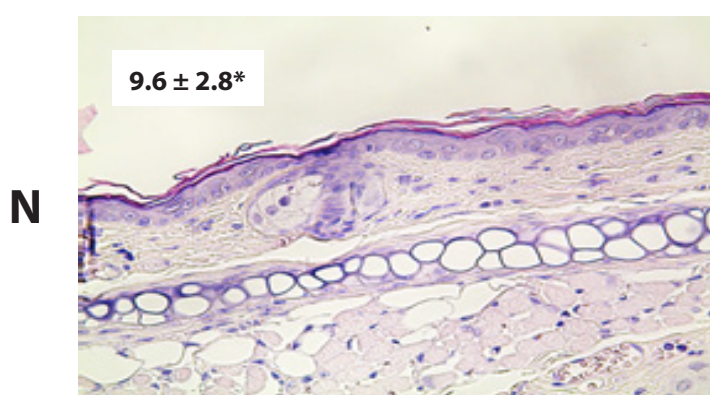

Toluidine blue

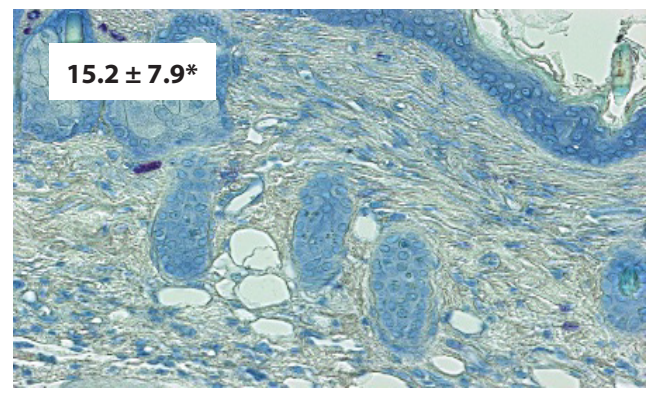

Figure 4. The histological examination of skin after treatment of ACWE in DNCB induced atopic-like dermatitis model. H\&E, toluidine blue stain, $\times$ 400. N: Non-treatment, C: DNCB, VC: Oxazolone + AOO (acetone : olive oil = 4: 1), PC: DNCB + 0.5\% Dexamethasone, T1: DNCB + ACWE 1\%, T2: DNCB + ACWE 6\%. Bar: $10 \mu \mathrm{M}$. Arrows are mast cells for Toluidine blue staining in $\mathrm{C}$ group. Epidermal thickness was determined by the average of three sites (short, medium, long-size each) in same fields of microscope for H\&E staining, and the number of mast cells was determined by the average of five different fields with an eyepiece for Toluidine blue staining. Values are mean \pm SD of skin epidermis thickness and mast cell numbers of 5 mice. ${ }^{*} p<0.05$ as compared to the $\mathrm{C}$ group by ANOVA and Tukey-Kramer test. 


\section{H\&E}

C

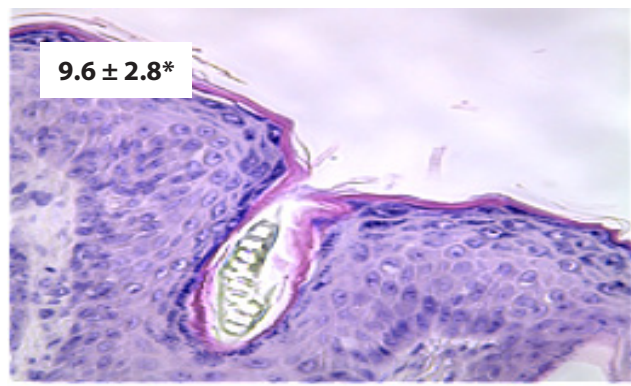

VC

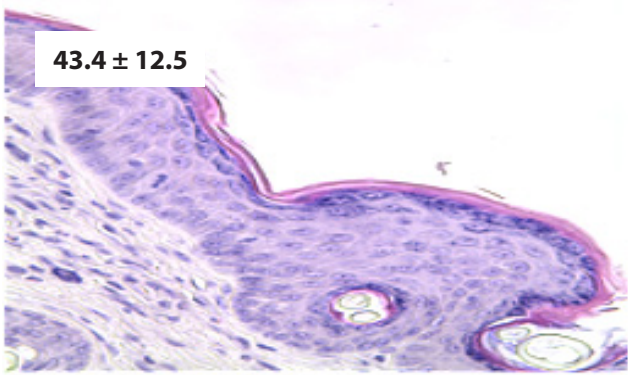

PC

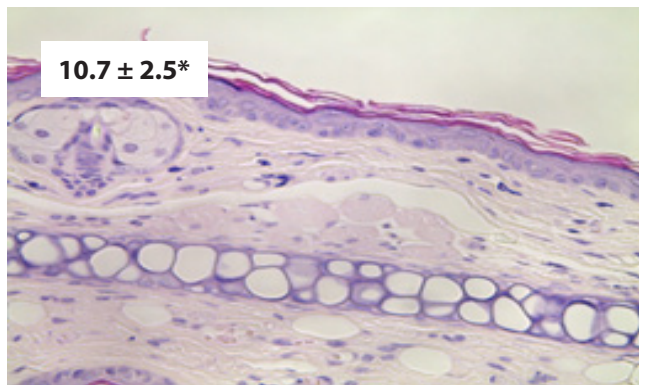

T1

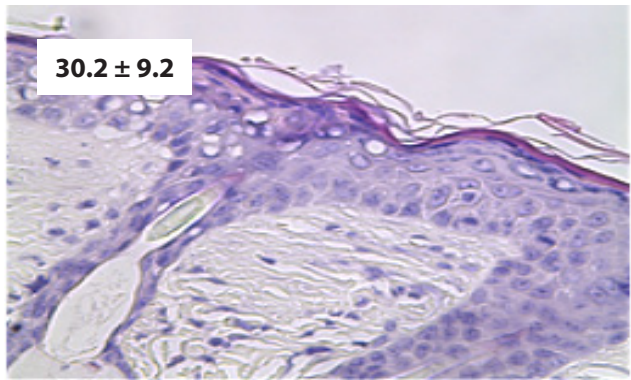

T2

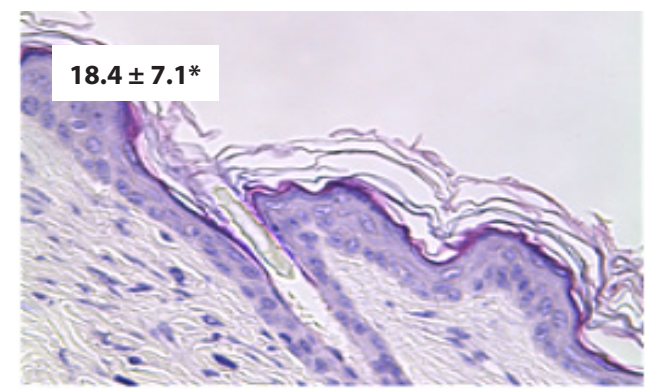

Toluidine blue
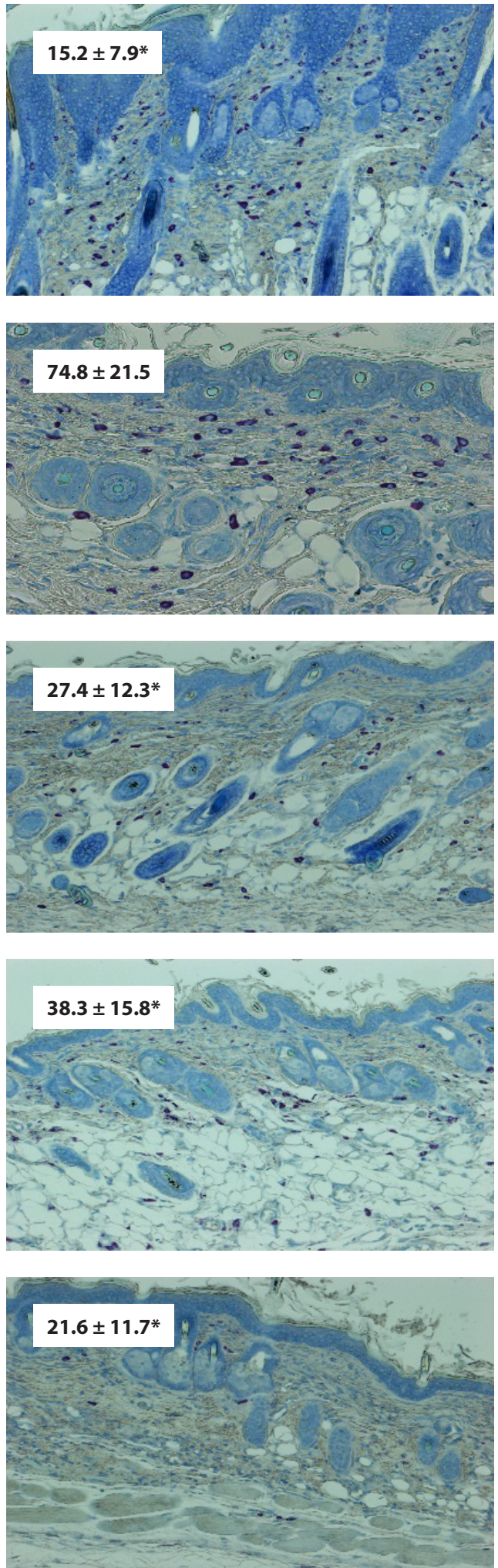

Figure 4. (Continued) 


\section{Microscopical observation based on H\&E, toluidine blue stain- ing}

In H\&E staining, Thickness of epidermis and infiltration of inflammatory cells were remarkably decreased in $\mathrm{T}$ and $\mathrm{PC}$ groups compared to those in $\mathrm{N}$ group. Mast cell expressions in toluidine blue staining were also decreased in $\mathrm{T}$ and $\mathrm{PC}$ groups compared to those in $\mathrm{C}$ and VC groups (Figure 4).

\section{Discussion}

Atopic dermatitis is also induced by epidermal water loss and reduced water content of skin when cornified skin barrier is damaged. It can result in skin dryness, itching, swelling, and scaly. ${ }^{25}$

To verify the anti-inflammatory and immune modulator effect of ACWE which has lot of anti-oxidant components, various in vitro and in vivo experiments were performed in this study. In antioxidant test, total polyphenol and total flavonoid contents of ACWE were high. Its electron donation ability and free radical scavenging activity were increased in a dose dependent manner.

LPS, an endotoxin constituting the cell wall of Gram-negative bacteria, can induce gene expression of inflammatory mediators, such as nitric oxide (NO) which is generated by inducible nitric oxide synthase (iNOS), and cyclooxygenase-2 (COX-2), through activating nuclear factor- $\kappa \mathrm{B}(\mathrm{NF}-\kappa \mathrm{B})$, a transcription factor in macrophages. ${ }^{26}$ It has been reported that a substance that can inhibit or modulate enzyme expression might be useful as an anti-inflammatory agent. ACWE inhibited LPS induced NO production which is induced by iNOS, a mediator of inflammatory reaction, in dose dependent manner. ${ }^{26}$

Oxazolone induced ear edema model using BALB/c mouse is usually used to test in vivo anti-inflammatory effect. ACWE reduced ear thickness and ear weight in dose dependently, and this is confirmed microscopically. These anti-inflammatory effects of ACWE is thought to be very meaningful in predicting the effects for atopy, because inflammation is major symptom of atopy. ${ }^{27}$

Atopic-like dermatitis model was induced by DNCB as a hapten. ${ }^{13}$ Effect of ACWE on DNCB-induced atopic-like dermatitis was evaluated by clarifying changes in clinical sign and immune function. Results of this study revealed that ACWE decreased the scratching frequency, TEWL, skin erythema and serum IgE levels which is important indicator of atopic dermatitis. Increased IL-4 level can promote IgE level which can activate mast cells to participate in skin reaction accompanied by pruritus and erythema in atopic dermatitis. ${ }^{28}$

$\mathrm{T}$ cell is also an important immunological marker that plays a key role in maintaining immune response by cell mediated response. ${ }^{29}$ IFN- $\gamma$, one of Th1 cytokines, can suppresses Th2 cell activation and IL-4 release that modulates humoral immune response. IFN- $\gamma$ will eventually lead to imbalanced humoral immune response. ${ }^{30}$

In this study using spleen cells, IFN- $\gamma$ levels were significantly increased, but IL-4 levels were significantly decreased in ACWE. These results suggest that ACWE treatment can improve the atopic symptoms by increasing Th1 cell response, and decreasing Th2 cell response. Although some reports showed IFN- $\gamma$ is known for the induction of skin inflammation, ${ }^{31}$ it is also known to suppress IgE synthesis, one of the major atopic symptoms, ${ }^{28}$ which may more strongly influence the reduction of skin inflammation.

Results of histopathological examination showed that epidermis thickness and inflammatory cell infiltration were markedly decreased, and infiltrations of mast cells were also decreased in ACWE treated groups compared to those in $\mathrm{C}$ and VC groups. Histopathologically, atopic dermatitis is caused by infiltration of inflammatory cells and edema in the skin $^{7}$ by histamine released after the binding of IgE to mast cells. ACWE treatment showed anti-inflammatory effects by diminishing mast cells.

In conclusion, ACWE showed high antioxidant effect with very low cytotoxicity in vitro, and had high anti-inflammatory effect in oxazolone-induced subacute skin inflammation animal model in vivo. In addition, ACWE was effective in helping the recovery of skin lesions and immunologic response in DNCB-induced atopic-like dermatitis model. Results of this study were thought to provide basic data supporting that ACWE might be useful as an agent for atopic dermatitis. The major component of the Aristotelia chilensis was known as anthocyanin which contained a lot of delphinidin, and it also has other flavonoids, alkaloids, cinnamic acid derivatives, benzoic acid derivatives, and other bioactive molecules. ${ }^{32}$ These components are thought to work together on the attenuation of dermatitis. But additional studies are needed to clarify the action mechanisms of the separate components in Aristotelia chilensis on atopic dermatitis, in the future.

\section{References}

1. Diepgen TL, Agner T, Aberer W, Berth-Jones J, Cambazard F, Elsner P, et al. Management of chronic hand eczema. Contact Dermatitis. 2007;57: 203-210.

2. Howell MD, Kim BE, Gao P, Grant AV, Boguniewicz M, Debenedetto A, et al. Cytokine modulation of atopic dermatitis filaggrin skin expression. J Allergy Clin Immunol. 2007;120: 150-5.

3. Han RT, Kim S, Choi K, Jwa H, Lee J, Kim HY, et al. Asthma-like airway inflammation and responses in a rat model of atopic dermatitis induced by neonatal capsaicin treatment. J Asthma Allergy. 2017;10:181-9.

4. Boguniewicz M, Leung DY. Atopic dermatitis: a disease of altered skin barrier and immune dysregulation. Immunol Rev. 2011;242:233-246.

5. Gray M, Black JM, Baharestani MM, Bliss DZ, Colwell JC, Goldberg M, et al. Moisture-associated skin damage: overview and pathophysiology. J Wound Ostomy Continence Nurs. 2011;38:233-241.

6. Platts-Mills TA. The role of immunoglobulin E in allergy and asthma. Am J Respir Crit Care Med. 2001;164:S1-5.

7. Leung DY, Soter NA. Cellular and immunologic mechanisms in atopic dermatitis. J Am Acad Dermatol. 2001;44(1 Suppl):S1-12.

8. Fallon PG, Ballantyne SJ, Mangan NE, Barlow JL, Dasvarma A, Hewett DR, et al. Identification of an interleukin (IL)-25-dependent cell population that provides IL-4, IL-5, and IL-13 at the onset of helminth expulsion. J Exp Med. 2006;203:1105-16.

9. Leung DY, Boguniewicz M, Howell MD, Nomura I, Hamid QA. New insights into atopic dermatitis. J Clin Invest. 2004;13:651-7.

10. Hoare C, Li Wan Po A, Williams H. Systematic review of treatments for atopic eczema. Health Technol Assess. 2000;4:1-191.

11. Ring J, Barker J, Behrendt H, Braathen L, Darsow U, Dubertret L, et al. Review of the potential photo-cocarcinogenicity of topical calcineurin inhibitors: position statement of the European dermatology forum. J Eur Acad Dermatol Venereol. 2005;19:663-71.

12. Rukwied R, Lischetzki G, McGlone F, Heyer G, Schmelz M. Mast cell mediators other than histamine induce pruritus in atopic dermatitis patients: a dermal microdialysis study. Br J Dermatol. 2000;142:1114-20. 
13. Lee SH, Baek SJ, Kim HA, Heo Y. 2,4-Dinitrochlorobenzene-induced atopic dermatitis like immune alteration in mice. J Toxicol Pub Health. 2006;22:357-64.

14. Park SJ, Cha HS, Lee YH, Kim WJ, Kim DH, Kim EC, et al. Effect of nodakenin on atopic dermatitis-like skin lesions. Biosci Biotechnol Biochem. 2014;78:1568-71.

15. Gironés-Vilaplana A, Valentão P, Moreno DA, Ferreres F, García-Viguera C, Andrade PB. New beverages of lemon juice enriched with the exotic berries maqui, açaí, and blackthorn: bioactive components and in vitro biological properties. J Agric Food Chem. 2012;60:6571-80.

16. Rojo LE, Roopchand DE, Graf B, Cheng DM, Ribnicky D, Fridlender B, et al. Role of anthocyanins in skin aging and UV-induced skin damage. In: Wallace TC, Giusti MM, editors. Anthocyanins in health and disease. Boca Raton (FL): CRC Press; 2013. p. 309-18.

17. Xiao JB, Högger P. Dietary polyphenols and type 2 diabetes: current insights and future perspectives. Curr Med Chem. 2015;22:23-38

18. Turrini E, Ferruzzi L, Fimognari C. Possible effects of dietary anthocyanins on diabetes and insulin resistance. Curr Drug Targets. 2017;18:629-40.

19. Folin O, Denis W. On phosphotungstic-phosphomolybdic compounds as color regents. J Biol Chem. 1912;12:239-43.

20. Blois MS. Antioxidant determinations by the use of a stable free radical. Nature. 1958;181:1199-200.

21 Kunz B, Oranje AP, Labrèze L, Stalder JF, Ring J, Taïeb A. Clinical validation and guidelines for the SCORAD index: consensus report of the European task force on atopic dermatitis. Dermatology. 1997;195:10-9.

22. Yoon SB, Lee YJ, Park SK, Kim HC, Bae H, Kim HM, et al. Anti-inflammatory effects of Scutellaria baicalensis water extract on LPS-activated RAW 264.7 macrophages. J Ethnopharmacol. 2009;125: 286-90.
23. Re R, Pellegrini N, Proteggente A, Pannala A, Yang M, Rice-Evans C. Antioxidant activity applying an improved ABTS radical cation decolorization assay. Free Radic Biol Med. 1999;26:1231-7.

24. Choi YY, Kim MH, Lee H, Jo SY, Yang WM. R)-(+)-pulegone suppresses allergic and inflammation responses on 2,4-dinitrochlorobenzene-induced atopic dermatitis in mice model. J Dermatol Sci[Preprint]. 2018 [cited 2018 Aug 24]. Available from: https://doi.org/10.1016/j.jdermsci.2018.06.002.

25. Park YL, Park J. Pathogenesis of Atopic Dermatitis. J Invest Dermatol. 2007;14:67-72.

26. Raso GM, Meli R, Di Carlo G, Pacilio M, Di Carlo R. Inhibition of inducible nitric oxide synthase and cyclooxygenase- 2 expression by flavonoids in macrophage J774A.1. Life Sci. 2001;68:921-31.

27. Blumenthal MN, Zhong W, Miller M, Wendt C, Connett JE, Pei D. Serum metalloproteinase leukolysin (MMP-25/MT-6): a potential metabolic marker for atopy-associated inflammation. Clin Exp Allergy. 2010;40:859-66.

28. Muro Y. Autoantibodies in atopic dermatitis. J Dermatol Sci. 2001;25:171-8.

29. Nuttall TJ, Knight PA, McAleese SM, Lamb JR, Hill PB. Expression of Th1, Th2 and immunosuppressive cytokine gene transcripts in canine atopic dermatitis. Clin Exp Allergy. 2002;32:789-95.

30. Grewe M, Bruijnzeel-Koomen CA, Schöpf E, Thepen T, Langeveld-Wildschut AG, Ruzicka T, et al. A role for Th1 and Th2 cells in the immunopathogenesis of atopic dermatitis. Immunol Today. 1998; 19:359-61.

31. Zhang G, Liu X, Wang C, Qu L, Deng J, Wang H, et al. Resolution of PMA-induced skin inflammation involves interaction of IFN- $\gamma$ and ALOX15. Mediators Inflamm. 2013;2013:930124.

32. Romanucci V, D’Alonzo D, Guaragna A, Di Marino C, Davinelli S, Scapagnini G, et al. Bioactive Compounds of Aristotelia chilensis Stuntz and their Pharmacological Effects. Curr Pharm Biotechnol. 2016;17:513-23. 